\title{
A rare complication of ureteral stenting: Case report of a uretero-arterial fistula and revision of the literature
}

\author{
Alois Mahlknecht ${ }^{1}$, Leonardo Bizzotto ${ }^{1}$, Christoph Gamper ${ }^{1}$, Anton Wieser ${ }^{2}$ \\ ${ }^{1}$ Department of Urology, Azienda Sanitaria dell'Alto Adige, Merano, Italy; \\ 2 Department of Radiology, Azienda Sanitaria dell'Alto Adige, Merano, Italy.
}

\begin{abstract}
Summary Introduction: Uretero-arterial fistulas are a rare condition. The most frequent clinical sign is hematuria. Since these bleedings occur intermittently, the diagnosis is very difficult. If not discovered, uretero-arterial fistulas involve a very high rate of mortality or even results in loss of kidney function.

Case report: The clinical case we describe is an unusual one. After a radical hysterectomy and a subsequent radiotherapy, a hydronephrosis caused by ureteral fibrosis occurred on both sides. Therefore, the patient received bilateral ureteral stents. During a change of the ureteral stents 18 months later, a massive bleeding appeared in the right ureter. Initially, a clear evidence of a fistula was not possible - neither through CT scan nor through selective angiography. There were some indicators of a uretero-arterial fistula, so an endoluminal vessel stent was placed. Subsequently the fistula probably led to an erosion of the vessel stent.

Discussion: A fistula between the ureter and the iliac artery (UAF) is a rare complication. The increase in known cases during the last years is linked to the possibility of ureteral stenting since 1978. Until now only 140 cases have been described in literature. The mortality rate through UAF has decreased from $69 \%$ in 1980 to $7-23 \%$ today. Its development can be traced through the pulsation of the artery and the pressure on the ureter. The most important clinical symptom is bleeding. Diagnosis is generally difficult and represents the real problem. The sensitivity of the standard angiography examination is 23$41 \%$; it can be improved to $63 \%$ using the "provocative" method, which means mobilizing the ureteral stent during examination. The therapy in course of the angiography consists of a simultaneous endovascular stent and/or a co-embolisation. Conclusion: Arterial or uretero-arterial fistulas (UAF) are a rare condition; the diagnosis is very difficult and most of the time the treatment requires a multidisciplinary team.
\end{abstract}

KEY WORDS: Ureteral stenting; uretero-arterial fistula.

Submitted 18 June 2018; Accepted 5 July 2018

\section{INTRODUCTION}

Uretero-arterial fistulas are a rare condition that can be critical in case of bleeding. Since these bleedings occur intermittently, the diagnosis is very difficult. If not discovered, uretero-arterial fistula involve a very high rate of mortality or even results in the loss of kidney function.

\section{Case report}

In 2004, the patient was 79 years old. Because of a welldifferentiated endometrial carcinoma, the patient under- went a radical hysterectomy, adnexectomy and a lymphadenectomy. Histological examination was a pT2b, N1, (2/19 positive lymph nodes), Mo, Gr I, Ro stage. Consequently, the patient underwent radiotherapy. During a control visit in September 2009, a fibrosis plate in the lower pelvis had become visible on the CT and MRI scans. This plate compressed both ureters and subsequently caused a hydronephrosis on both sides.

The hydronephrosis was more evident on the right side and caused a chronic kidney failure. Therefore, the kidney was drained. Silicon TU-stents of Opti-Med, $7 \mathrm{Ch}$, $28 \mathrm{~cm}$ were used.

The hydronephrosis never receded entirely and a recurrent urinary tract infection with fever occurred. Furthermore, the patient suffered from several additional pathologies, e.g. diabetes mellitus type II, a chronic cardiomyopathy and a diffuse vasculopathy.

During a programmed change of the ureteral stent in March 2011, a massive bleeding in the right ureter suddenly arose. Through the quick change of the stent a spontaneous tamponade was made. After stabilizing the cardiovascular system and correcting the heavy loss of blood, a CT scan followed by a selective intra-arterial angiography in digital technique were carried out.

Both examinations showed an ureteroarterial fistula between the right common iliac artery and the ureter; however, a clear evidence could not be found. During the examination, the common and the external iliac artery were successfully repaired. Additionally, the internal iliac artery was closed.

Eight months later, an intermittent macrohematuria occurred again and this time, the "provocative" angiography clearly showed a fistula and also the retrograde pyelography also confirmed a contrast medium leakage (Figures 1, 2). With high probability, the fistula was caused by the erosion of the ureteral endoluminal stentgraft. A covering through a second stent was made.

In May 2012, a definitive, percutaneous nephrostomy was placed on the right side as additional changes of the ureteral stents would surely have increased the risk of new bleedings.

Four months later, a severe macrohematuria occurred again. Therefore, another endografting of the right common iliac artery with a Fluency 10x100 covered stent was placed (Figure 3).

The patient died two months later - probably due to pulmonary embolism. 

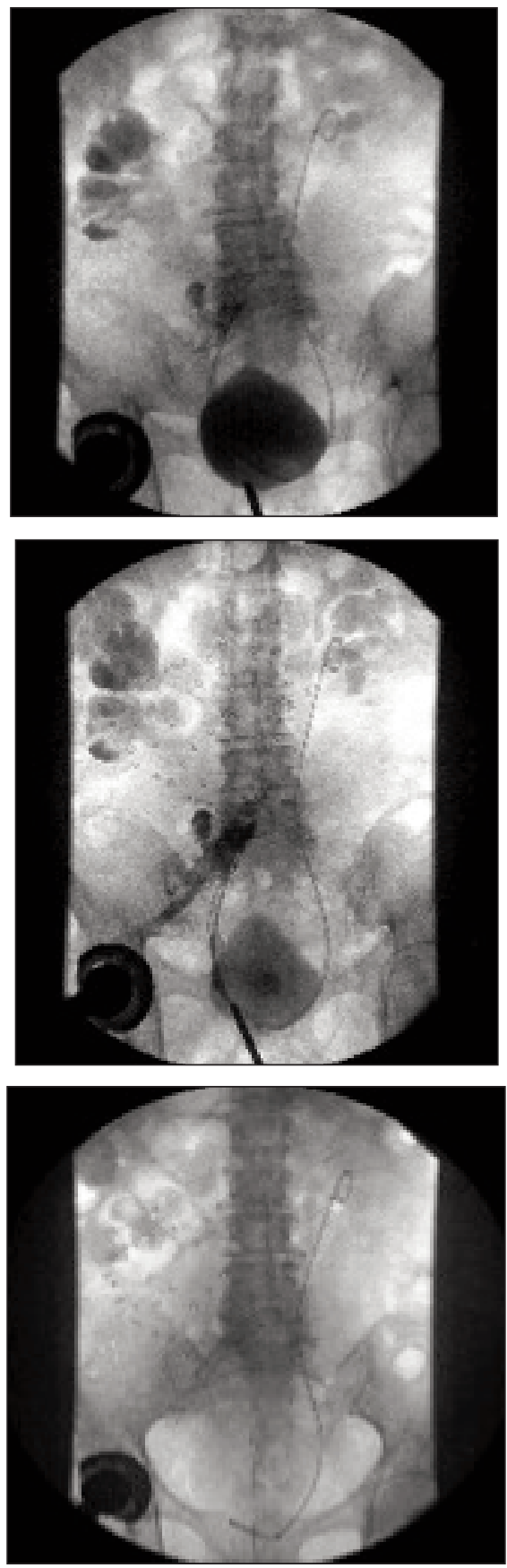

Figure 3.

Four months later a Fluency $10 \times 100$ covered stent was placed.

\section{Discussion}

A fistula between the ureter and the iliac artery (UAF) is a rare complication. The first presentation took place in New York in 1908 when Moschcowitz presented a case in which a patient underwent a ureterostomy on both sides and postoperatively developed an erosion on both sides in the external iliac artery caused by a ureteral stone. Both vessels were ligated above and below the lesions (1).

The increase in known cases during the last years is linked to the possibility of ureteral stenting since 1978 (2). However, uretero-arterial fistulas are a rare condition (3). Until now only 140 cases have been described in literature. The mortality rate through UAF has decreased from $69 \%$ in 1980 to $7-23 \%$ today.
The uretero-arterial fistula (UAF) arises where the ureter and the common or external iliac artery meet. Its development can be traced through the pulsation of the artery and the pressure on the ureter. Above, the edema develops into a necrosis to the ureter wall and eventually into a fistula $(5,6)$. With an intact wall and mucosa a fistula will not develop. There must be predisposal factors and/or risk factors. Indeed, inflammatory reactions after surgery to the ureter wall, local fibrosis of the retroperitoneum after radiotherapy or vascular surgery in the pelvic area can lead to adhesions between the ureter and artery, which then will cause the formation of a fistula (7). However, most of the time fistulas arise after the placement of ureteral stents (8). Especially when they lie for a long time, fistulas can develop; even the harder polyethylene stents, which are easier to position, seem to cause fistulas more easily. Generally, the period between the positioning of a stent and the formation of a fistula can last between 1 up to 8 years (9). Additionally, oncological surgeries in the pelvis (cervix, uterus, and bladder), radiotherapy and vascular surgeries are risk factors for the formation of fistulas (10). A rupture of the vasa vasorum and the weakening of the tunica media and the adventitia of the bigger arteries could be probable causes (11).

Other factors are rare exceptions - for example the surgical drainage after an appendectomy or ureterotomy, where the mechanical pressure of the drain creates a simultaneous inflammatory reaction; or the spontaneous rupture of an aneurysm in the ureter $(12,13)$. Several other factors play a significant role, e.g. in the case description of Taylor and Reinhard, in which a mycotic aneurysm of the common iliac artery ruptured into the ureter which had a ureteral stent lying for 24 days (14). The most important clinical symptom is bleeding. In most cases, it is intermittent bleeding, in which the thrombosis closes the fistula in the meantime.

Diagnosis is generally difficult and represents the real problem. Through sonogram, urography and CT scan the uretero-arterial fistula cannot be shown. The CT scan has low sensitivity and it is not sufficient as the only imaging technique (8). Furthermore, the results of the antegrade or retrograde pyelography are questionable. The cystoscopy with retrograde pyelography has a sensitivity of $45-60 \%$ (15). Only angiography is relatively suitable for diagnosis. The sensitivity of standard angiography examination is $23-41 \%$; it can be improved to 63\% using the "provocative" method, which means mobilizing the ureteral stent during examination (16).

The angiography shows evidence of fistulas only during the bleeding phase. If a sonogram or urography shows blood coagula in the renal pelvis-calyceal system in a patient with a lying stent, a uretero-arterial fistula could be the cause (17). Therefore, the sonography can give first diagnostic indication.

First of all, the therapy depends on the quality of the preoperative diagnosis. If not made correctly and carefully, $32 \%$ of the patients consequently suffer from the loss of the kidney through nephrectomy or embolisation (16). With certain diagnosis the therapy consists of supplying the arterial lesion. The ureter does not necessarily have to be repaired $(5,6)$. The surrounding circumstances are decisive for the choice of therapy: stitching over the 
lesion, embolising or rather ligating the iliac artery with or without bypass, and interpositioning of a vascular prosthesis. When embolising, the danger of inadequate blood supply of the lower extremities has to be kept in mind; therefore, a vascular surgery to create a bypass is absolutely necessary. In some circumstances, fibrotic changes after preceding surgery and/or radiotherapy as well as recurrent tumours can militate against reconstruction. If these factors do not exist, a direct supply of the artery should be favoured. Alternatively, the arterial embolisation of the common iliac artery is recommended. Since 1996 endovascular methods have been at hand they are less invasive and are nowadays therapeutic standard (18-20). Indeed, in the course of angiography a simultaneous endovascular supply of the fistula through implantation of a covered stent and/or co-embolisation should be favoured. Its advantages are obvious: interventional application without surgery and a low operative risk with physiological maintenance of the arterial bloodstream. The only disadvantage is the risk of infection.

\section{Conclusions}

Arterial or uretero-arterial fistulas (UAF) are a rare condition. Until now, about 140 cases have been described. Through the increase of gynecological, urological and vascular surgeries in the lesser pelvis and, above all, through the introduction of ureteral stents in 1978, an exponential increase of the cases has been recorded. Therefore, for stenting it is recommended to use soft stents and stents that are smaller in diameter when stenting $(21,22)$.

The leading symptom is the massive, mostly intermittent hematuria. If untreated, mortality comes up to $100 \%$.

A careful anamnesis and diagnosis are preconditions for a successful therapy. Uretero-arterial fistulas arise only when predisposal risk factors like ureteral stents and pelvic pre surgeries occur, or after radiation. Through selective selective angiography as digital subtraction technique, clear evidence of the cause of the bleeding can be obtained in the majority of the cases. Furthermore, in the course of the same examination an endovascular therapy can be made The case of an uretero-arterial fistula after ureteral stenting on the right side has been described above. The fistula had been successfully treated three times.

The very high mortality rate of $67 \%$ until 1978 decreased to $17 \%$ in 1996 through the introduction of endovascular treatment. In view of the good results as well as the patient's limited life expectancy because of a malign underlying disease, the endovascular treatment should be the therapy of choice.

\section{References}

1. Moschcowitz AV. Simultanous ligation of both external iliac arteries for secondary hemorrhage following bilateral ureterolithotomy. Ann Surg. 1908; 48:872.

2. Finney RP. Experience with new double J ureteral catheter stent. J Urol. 1978; 120:678.

3. Bettman MA, Murray PD, Perlmutt LM, et al. Uretero-iliacal anastomotic leaks: percutaneous treatment. Radiology. 1983; 148:95.

4. Batter SJ, McGovern FJ, Cambria RP. Uretroarterial fistula: case report and review of the literature. Urology 1996; 48:481.
5. Keller FS, Barton RE, Routh WD, Gross GM. Gross hematuria in two patients with ureteral-ileal conduits and double-J stents. J Vasc Intervent Radiol. 1990; 1:69.

6. Toolin E, Pollack HM, Mc Lean GK, et al. Uretero-arterial fistula: a case report. J Urol. 1984; 132:553.

7. Reiner RJ, Conway GF, Threlkeld R Ureteroarterial fistula J Urol. 1975; 116:111.

8. Krambeck AE, DiMarco DS, Gertman MT, et al. Ureteroiliac artery fistula: diagnosis and treatment algorithm. Urology. 2005; 66:990.

9. Puppo P, Perachino M, Ricciotti G, et al. Ureteroarterial fistula: a case report. J Urol. 1992; 148:863.

10. Vandersteen DR, Saxon RR, Fuchs E, et al Diagnosis and management of ureteroiliac artery fistula: value of provocative arteriography followed by common iliac artery embolization and extraanatomic arterial bypass grafting. J Urol. 1997; 158:748.

11. Dervanian P, Castaigne D, Travagli JP, et al. Arterioureteral fistula after extendet resection of pelvic tumors: report of three cases and review of the literature. Ann Vasc Surg. 1992; 6:362.

12. Martinez VMB, Gomez AEM. Postappendectomy aretrio-ureteral fistula. Actas Urol Esp. 1980; 4:331.

13. Rennick JM, Link DP, Palmer JM. Spontaneous rupture o fan iliac artery aneurysm into an ureter: a case report and review of the literature. J Urol. 1976; 116:111.

14. Taylor WN, Reinhart HL. Mycotic aneurysm of common iliac artery with rupture into right ureter: report of a case. J Urol. 1939; $42: 24$.

15. Quillin SP, Darcy MD, Picus D. Angiographic evaluation and therapy of arterioureteral fistulas. Am J Roentg 1994; 162:873.

16. Vandersteen DR, Saxon RR, Fuchs E, et al. Diagnosis and management of uretroureteral fistula: value of provocative arteriography followed by common iliac artery embolization and extraanatomic arterial bypass grafting. J Urol. 1997; 158:748.

17. Hausegger von KA, Sonnleitner J, Uggowitzer M, et al. Iliakouretrale Fistel, eine seltene Komplikation bei Ureterschienung. Fortschr Roentgenstr. 1996; 164:525.

18. Bilbao JI, Cosin O, Bastarrika G, et al. Treatment of ureteroarterial fistulae with covered vascular endoprothesis and ureteral occlusion. Cardiovasc Intervent Radiol. 2005; 28:159.

19. Araki T, Nagata M, et al. Endovascular treatment of ureteroarterial fistulas with stent-grafts. Radiat Med. 2008; 26:372.

20. Krenzien J, Zimmermann HB, Schott H. Die iliaco-ureterale Fistel und ihre Behandlung mit einem Stent-Graft Der Chirurg. 1998; 69:977-980.

21. Zweers HMM, Driel van MF, Mensink HJM. Iliac artery- ureteral fistula associated with an indwelling ureteral stent. Urol Int. 1991; 46:213.

22. Sparwasser C, Kugler A, Gilbert P, et al. Bilaterale uretero-iliakale Fisteln in Zusammenhang mit Radiatio und ureteraler Splintung. Urologe A. 1994; 33:85.

\section{Correspondence}

Alois Mahlknecht, MD

alois.mahlknecht@sabes.it

Leonardo Bizzotto, MD

Christoph Gamper, MD

Department of Urology, Azienda Sanitaria dell'Alto Adige, Merano, Italy

Anton Wieser, MD

Department of Radiology, Azienda Sanitaria dell'Alto Adige,

Merano, Italy 